\title{
Rheological Characterization of Bentonite Dispersions with Xanthan for Oil Well Drilling Fluids
}

\author{
Gabriel Sahade de Souza ${ }^{a}$, Samuel Luporini ${ }^{b}$, Isabel Cristina Rigolic \\ ${ }^{a}$ Universidade Petrobras, Petróleo Brasileiro S.A. 41850-903, Salvador, BA, Brazil \\ ${ }^{b}$ Laboratory of Polymer Engineering (Lepol), Chemical Engineering Department, Universidade \\ Federal da Bahia - UFBA, 40210-630, Salvador, BA, Brazil \\ ${ }^{c}$ Physical Chemistry Department,Chemistry Institute, Universidade Federal da Bahia - UFBA, \\ 40170-115, Salvador, BA, Brazil
}

Received: October 10, 2016; Revised: April 11, 2017; Accepted: May 21, 2017

\begin{abstract}
Shear tests using a coaxial cylinders viscometer were performed in order to determine the rheological and thixotropic properties of xanthan gum dispersions with sodium bentonite in the presence of high salt concentrations of sodium and calcium chlorides. The dispersions rheology with different temperatures and concentrations of $\mathrm{NaCl}, \mathrm{CaCl}_{2}$ and xanthan gum were prepared by fixing the bentonite concentration of $1 \%$. The dispersions showed a good fit to power law model through linear regressions with the lowest coefficient of determination value of 0,98 . A screening was made initially to decide which independent variables potentially affect the rheological and thixotropic parameters. The independent variables were temperature, the xanthan gum and sodium and calcium chlorides concentrations. Then a full factorial design in duplicate with the remaining variables on the same tracks was performed. The results eliminated calcium chloride as an independent variable and revealed a strong dependence of the rheological and thixotropic parameters with temperature and xanthan gum and $\mathrm{NaCl}$ concentrations.
\end{abstract}

Keywords: Rheology, Xanthan gum, Drilling fluids

\section{Introduction}

The well drilling is a process that aims not only to produce oil and gas, but also the injection of fluids to assist in the recovery of hydrocarbons.

In the current national scene, most of the oil and gas discovered can only be accessed by drilling offshore wells. The drilling fluid has a critical role in achieving this goal, so that it should meet operational, environmental and economic demands.

Drilling fluids are complex mixtures of solids, liquids, chemicals, and sometimes even gases. From a chemical point of view, drilling fluids can assume aspects of colloidal dispersion or emulsion, depending on the physical state of its components ${ }^{1}$. They are traditionally classified according to their base, which may be aqueous, non-aqueous, or gaseous.

Nowadays drilling fluids have been the subject of several discussions between researchers, oil industry companies and environmental agencies. The main point of discussion is to find solutions to problems caused by environmental contamination and geological formations bearing oil or water (aquifers). Aqueous fluids are generally much less aggressive to the environment than non-aqueous, usually discarded into the sea, when drilling offshore wells.

The primary functions of drilling fluids are removing and carrying the drilled rock fragments (cuttings), controling formation pressures and maintaining well stability. The

* e-mail: gabrielsahade@petrobras.com.br rheological and thixotropic properties of drilling fluids are very important for them to perform effectively their functions ${ }^{2}$.

Bentonite is a clay used in aqueous based drilling fluids in order to control their rheological and filtration properties. An increase in viscosity of the drilling fluid is closely related to a good transport downhole cuttings to the surface. However, the use of bentonite as viscosifier should be done with caution. High concentrations of this additive may cause problems, such as increasing column prison chances and torque of the drilling string due to friction ${ }^{3}$. To increase the viscosity of the fluid without increasing the concentration of bentonite, other viscosifying polymer additives are used as well. One of the major polymers used in conjunction with bentonite is xanthan gum.

Xanthan gum is a biopolymer used in the petroleum industry whose main objective is to increase the viscosity of aqueous based drilling fluids. Its high efficiency under conditions of high temperatures and salinity makes this polymer one of the most commonly used viscosifying agent in drilling fluids ${ }^{4}$.

Rheology is the study of deformation and flow of materials. The rheological model used in this study to characterize the fluid flow was power law model, shown in Equation 1

$$
\tau=k \cdot \dot{\gamma}^{n}
$$

Where " $\tau$ " is the shear stress, " $k$ " is the flow consistency index, " $\dot{\gamma}$ " is the shear rate, and " $n$ " is the flow behavior index. 
Thixotropy is the phenomenon of gelation of the fluid when left for a certain period of static and its return to its fluid state when subjected to shear stress. The two main thixotropic parameters used in the petroleum industry are the initial gel strength $\left(\mathrm{G}_{10 \mathrm{~s}}\right)$ and the final gel strength $\left(\mathrm{G}_{10 \mathrm{~m}}\right)$ representing, respectively, the magnitudes of gelation forces the fluid undergoes within a period of ten seconds and ten minutes ${ }^{5}$. This property is important for drilling fluids because it prevents cuttings decantation downhole in static periods ${ }^{1}$.

The current study aims to investigate the effects of temperature and concentrations of monovalent and divalent ions in the rheological (" $k$ " and " $n$ ") and thixotropic $\left(\mathrm{G}_{10 \mathrm{~s}}\right.$ and $\mathrm{G}_{10 \mathrm{~m}}$ ) parameters of xanthan gum with bentonite dispersions in order to use this polymer as a viscosifying agent in aqueous based drilling fluids.

\section{Materials and Methods}

Xanthan gum (Sigma-Aldrich, USA), sodium chloride (Quimis with 99\% PA), calcium chloride dihydrate (Quimis with 99\% PA), sodium bentonite (DRESCON SA) and deionized water were used as raw materials to prepare the samples. The physical and chemical characteristics of xanthan gum and sodium bentonite are shown in Tables 1 and 2, respectively.

Table 1. Characteristics of xanthan gum.

\begin{tabular}{cc}
\hline Characteristic & Values \\
\hline Molecular Weight estimated (g.gmol $\left.{ }^{-1}\right)$ & $4 \times 10^{6}$ \\
Acetate content (\%) & 3,53 \\
Pyruvate content (\%) & 0,9 \\
Viscosity (Brookfield @ 1\%) (cP) & $800-1200$ \\
\hline
\end{tabular}

Table 2. Characteristics of sodium bentonite.

\begin{tabular}{cc}
\hline Characteristic & Values \\
\hline Humidity (\%) & 10 \\
Granulometry 200 Mesh (\%) & $5-9$ \\
$\mathrm{pH}$ & $9-10$ \\
\hline
\end{tabular}

The Fann 35A viscometer was used for measurement of rheological and thixotropic parameters. Samples were prepared in Hammilton Beach stirrer model 936 with 13000 rpm for 5 minutes each addition of components ${ }^{6}$. After preparation the dispersions were stored at approximately $3^{\circ} \mathrm{C}$ for a period of 24 hours before use.

During the preparation of samples both xanthan gum as bentonite were dispersed in aqueous medium prior to placement of the salts in the system in order to facilitate hydration of the viscosifying agents.

The methodology of this study is divided into two parts. A sorting step and, subsequently, a thorough planning.
The screening step was a fractional factorial design $2^{(4-1)}$ with a center point. The screening input variables were the concentrations of xanthan gum $(\mathrm{XG})$, sodium $(\mathrm{NaCl})$ and calcium $\left(\mathrm{CaCl}_{2}\right)$ chlorides and the temperature $(\mathrm{T})$. The output variables were the flow consistency $(k)$ and flow behavior $(n)$ indexes (rheological parameters) and the initial and final gels forces (thixotropic parameters). This process was made in order to minimize the number of complete analysis experiments?

With the result of the screening stage, it was made a full factorial design $2^{3}$ with the remaining variables with two center points. Table 3 shows the real and coded variables (temperature and mass concentrations) for both performed plans. STATISTICA $7.0^{\circledR}$ was used in both designs.

Table 3. Factorial design variables and levels, where $(-1)$ is the lower level; (0), the midpoint; and $(+1)$, the upper one.

\begin{tabular}{ccccc}
\hline Level & $\mathrm{GX}(\%)$ & $\mathrm{T}\left({ }^{\circ} \mathrm{C}\right)$ & $\mathrm{NaCl}(\%)$ & $\mathrm{CaCl}_{2}(\%)$ \\
\hline-1 & 0,39 & 25 & 11,58 & 0,373 \\
0 & 0,43 & 50 & 12,86 & 0,414 \\
+1 & 0,47 & 75 & 14,14 & 0,455 \\
\hline
\end{tabular}

The chosen ranges of independent variables were selected according to the drilling fluids composition usually found in the field during drilling operations. The concentration of bentonite was kept constant at $1 \%$ as suggested by the literature. Fluids with bentonite concentrations greater than $1 \%$ present significant yield shear stress, which changes the power law model used ${ }^{4}$.

The codified mathematical model for the $2^{3}$ factorial design is displayed in Equation 2, where $\mathrm{Y}$ is the response (rheological or thixotropic parameter), $x_{i}$ are the input variables, $b_{0}$ is the global mean and $b_{i}$ and $b_{i j}$ are regression coefficients.

$$
\begin{aligned}
& Y=b_{0}+b_{1} \chi_{1}+b_{2} \chi_{2}+b_{3} \chi_{3}+ \\
& b_{12} \chi_{1} \chi_{2}+b_{13} \chi_{1} \chi_{3}+b_{23} \chi_{2} \varkappa_{3}
\end{aligned}
$$

The variance analysis (ANOVA) was performed to determine the significance at a 95\% confidence limit for each parameter $\left(k, n, \mathrm{G}_{10 \mathrm{~s}}\right.$ and $\left.\mathrm{G}_{10 \mathrm{~m}}\right)$ and the the response surface methodology was used in order to evaluate the thixotropic and reological parameters behaviours? ${ }^{7}$.

Analysis of Variances (ANOVA) is a statistical method that is used for assessing relationships and differences among the means of two or several data sets. The significant level of the data sets is determined by evaluating the F-Statistic and comparing it to the F-critical value for the samples. If the F-Statistic $(\mathrm{F})$ is larger than F-critical, in other words, the ratio $\mathrm{F} / \mathrm{F}$-critical is greater than 1.0 , then the variation between the groups is statistically significant. The level of significance $(\alpha)$ used in this research was 0.05 . 


\section{Results and Discussions}

The fractional factorial design $2^{(4-1)}$ with one center point and its measures are shown in Table 4 below. As can be seen by Pareto charts in Figures 1 and 2, both rheological and thixotropic parameters are not influenced by the concentration of calcium chloride at a confidence level of $95 \%$. Therefore, the calcium chloride concentration was ignored in the next step.
After calcium chloride elimination as an independent variable, a complete factorial design $2^{3}$ in duplicate with two central points was performed. Its results are shown in Table 5.

For a complete study, an analysis of variance (ANOVA) for each of the output variables was made. As displayed in Table 6 , in the case of variance analysis of temperature, the ratio $\mathrm{F} / \mathrm{F}$-critical is greater than 1.0 and also, the $\mathrm{p}$-value is smaller than the assumed value $(\alpha)$ of 0.05 . The same can

Table 4. Fraction factorial design $2^{(4-1)}$.

\begin{tabular}{cccccccc}
\hline $\mathrm{T}$ & $\mathrm{GX}$ & $\mathrm{NaCl}$ & $\mathrm{CaCl}_{2}$ & $n$ & $k\left(\mathrm{~Pa} \cdot \mathrm{s}^{\mathrm{n}}\right)$ & $\mathrm{G}_{10 \mathrm{~s}}(\mathrm{~Pa})$ & $\mathrm{G}_{10 \mathrm{~m}}(\mathrm{~Pa})$ \\
\hline-1 & -1 & -1 & -1 & 0,324 & 1,180 & 4,0 & 6,0 \\
+1 & -1 & -1 & +1 & 0,345 & 0,882 & 3,0 & 4,5 \\
-1 & +1 & -1 & +1 & 0,290 & 2,169 & 6,0 & 10,0 \\
+1 & +1 & -1 & -1 & 0,269 & 1,629 & 4,5 & 7,0 \\
-1 & -1 & +1 & +1 & 0,353 & 0,866 & 3,0 & 4,5 \\
+1 & -1 & +1 & -1 & 0,386 & 0,578 & 2,5 & 3,5 \\
-1 & +1 & +1 & -1 & 0,294 & 1,897 & 5,5 & 9,5 \\
+1 & +1 & +1 & +1 & 0,342 & 1,003 & 3,5 & 4,5 \\
0 & 0 & 0 & 0 & 0,319 & 1,293 & 4,5 & 6,0 \\
\hline
\end{tabular}

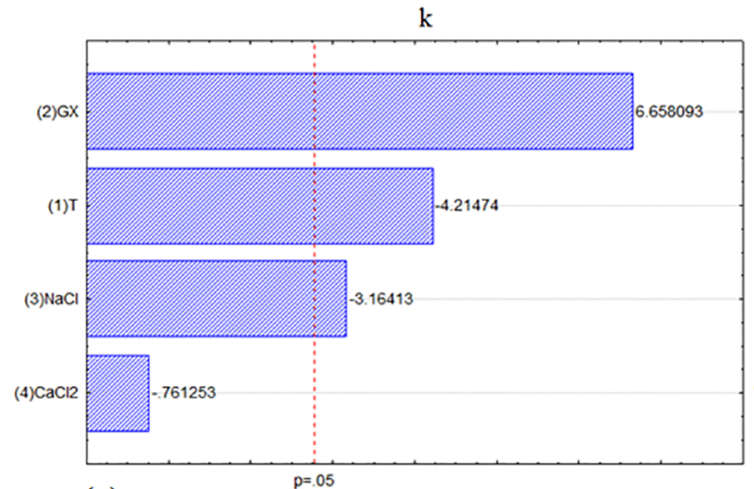

(a)

\section{Standardized effect}

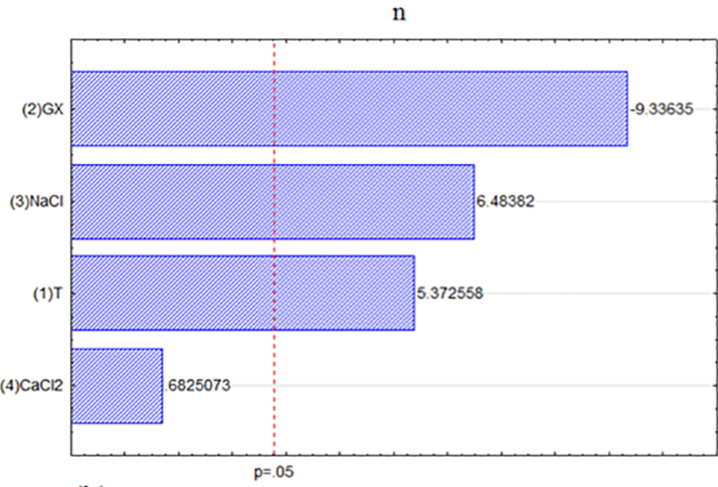

(b)

\section{Standardized effect}

Figure 1. Pareto charts for flow consistency (a) and flow behavior (b) indexes with a confidence level of $95 \%$.

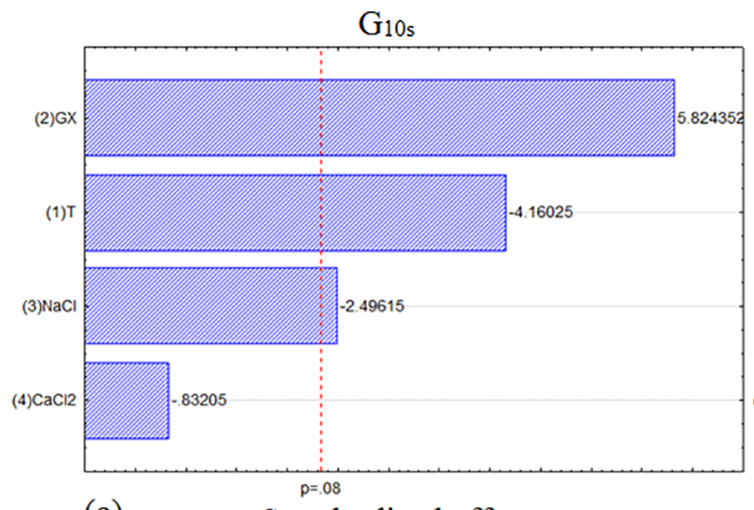

(a)

Standardized effect

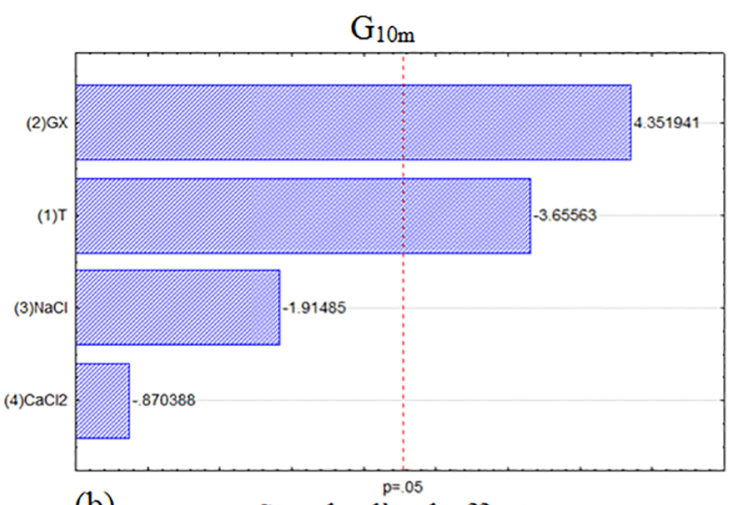

(b)
Standardized effect

Figure 2. Pareto charts for initial (a) and final (b) gel strenghts with a confidence level of $95 \%$. 
Table 5. Complete factorial design $2^{3}$ with two center points.

\begin{tabular}{ccccccc}
\hline $\mathrm{T}$ & $\mathrm{GX}$ & $\mathrm{NaCl}$ & $n$ & $k\left(\mathrm{~Pa} \cdot \mathrm{s}^{\mathrm{n}}\right)$ & $\mathrm{G}_{10 \mathrm{~s}}(\mathrm{~Pa})$ & $\mathrm{G}_{10 \mathrm{~m}}(\mathrm{~Pa})$ \\
\hline-1 & -1 & -1 & 0,324 & 1,180 & 4,0 & 6,0 \\
+1 & -1 & -1 & 0,345 & 0,882 & 3,0 & 4,5 \\
-1 & +1 & -1 & 0,290 & 2,169 & 6,0 & 10,0 \\
+1 & +1 & -1 & 0,269 & 1,629 & 4,5 & 7,0 \\
-1 & -1 & +1 & 0,353 & 0,866 & 3,0 & 4,5 \\
+1 & -1 & +1 & 0,386 & 0,578 & 2,5 & 3,5 \\
-1 & +1 & +1 & 0,294 & 1,897 & 5,5 & 9,5 \\
+1 & +1 & +1 & 0,342 & 1,003 & 3,5 & 4,5 \\
0 & 0 & 0 & 0,319 & 1,293 & 4,5 & 6,0 \\
-1 & -1 & -1 & 0,323 & 1,167 & 4,0 & 5,5 \\
+1 & -1 & -1 & 0,349 & 0,878 & 3,0 & 4,5 \\
-1 & +1 & -1 & 0,304 & 2,034 & 6,5 & 10,0 \\
+1 & +1 & -1 & 0,293 & 1,534 & 4,5 & 6,5 \\
-1 & -1 & +1 & 0,307 & 1,210 & 3,5 & 4,5 \\
+1 & -1 & +1 & 0,340 & 0,710 & 2,5 & 4,0 \\
-1 & +1 & +1 & 0,306 & 1,860 & 6,0 & 9,5 \\
+1 & +1 & 0 & 0,348 & 0,996 & 4,0 & 5,0 \\
\end{tabular}

Table 6. ANOVA analysis of flow index (n).

\begin{tabular}{lccccc}
\hline Source of variation & $\mathrm{SS}$ & $\mathrm{df}$ & $\mathrm{MS}$ & F/F-critical & p-value \\
\hline Temperature (T) & 0.003 & 1 & 0.003 & 11.9 & 0.000 \\
Xanthan Gum (XG) & 0.008 & 1 & 0.008 & 27.2 & 0.000 \\
$\mathrm{NaCl}$ & 0.004 & 1 & 0.004 & 12.7 & 0.000 \\
$\mathrm{~T} \times \mathrm{XG}$ & 0.000 & 1 & 0.000 & 0.0 & 0.959 \\
$\mathrm{~T} \times \mathrm{NaCl}$ & 0.001 & 1 & 0.001 & 0.9 & 0.033 \\
$\mathrm{XG} \times \mathrm{NaCl}$ & 0.000 & 1 & 0.000 & & 0.128 \\
Error & 0.001 & 11 & 0.000 & $\mathrm{R}^{2}$ & 0.937 \\
Total & 0.017 & 17 & - & & \\
\hline
\end{tabular}

be seen for xanthan gum and $\mathrm{NaCl}$ concentrations and the interaction of temperature with $\mathrm{NaCl}$ concentration. In the case of variance analysis of interactions of xanthan gum concentration with temperature and $\mathrm{NaCl}$ concentration, the ratios F/F-critical are smaller than 1.0 and also, the p-values are higher than the assumed value $(\alpha)$. It can be concluded that the effects of temperature, xanthan gum and $\mathrm{NaCl}$ concentrations and the interaction of temperature with $\mathrm{NaCl}$ concentration are significant, whereas the interactions of xanthan gum concentration with temperature and $\mathrm{NaCl}$ concentration have no significance on " $n$ ".

Tables 7-9 present the analysis of flow consistency index, initial and final gel strenghts, respectively. From multivariate regressions, we can generate analytical expressions that quantitatively correlates input variables encoded (temperature, xanthan gum and $\mathrm{NaCl}$ concentrations) with the output variables (n, k, $\mathrm{G}_{10 \mathrm{~s}}$ and $\mathrm{G}_{10 \mathrm{~m}}$ ), such as Equations 3, 4, 5 and 6.

$$
\begin{aligned}
& n=0,325+0,014 . \mathrm{T}-0,022 . G X+ \\
& \text { 0,015.NaCl+0,006.T.NaCl}
\end{aligned}
$$

$$
\begin{aligned}
& k=1,287-0,261 . T+0,353 . X G- \\
& \text { 0,147.NaCl-0,089.T.XG- } \\
& \text { 0,058.T.NaCl-0,054.XG.NaCl } \\
& G_{10 S}+8,389-1,375 \cdot T+1,875 . G X- \\
& \text { 0,625.NaCl-0,500.T.GX } \\
& G_{10 m}=12,389-2,500 . T+3,125 . G X- \\
& \text { 1,125.NaCl-1,500.T.GX }
\end{aligned}
$$

As seen in Tables 6-9, the correlation coefficients values were greater than 0.937 for all output variables, indicating that there is a good fit for all models. Not all effects were significant for all parameters at a confidence level of $95 \%$.

As discussed before, not all effects were significant for flow behavior index at a significance level of $95 \%$. Interactions of xanthan gum concentration with temperature and $\mathrm{NaCl}$ concentration didn't influence significantly " $n$ ". 
Table 7. ANOVA analysis of flow consistency index $(k)$.

\begin{tabular}{|c|c|c|c|c|c|}
\hline Source of variation & SS & df & MS & F/F-Critical & p-value \\
\hline Temperature $(\mathrm{T})$ & 1.089 & 1 & 1.089 & 39.1 & 0.000 \\
\hline Xanthan Gum (XG) & 1.996 & 1 & 1.996 & 71.4 & 0.000 \\
\hline $\mathrm{NaCl}$ & 0.346 & 1 & 0.346 & 12.8 & 0.000 \\
\hline $\mathrm{T} \times \mathrm{XG}$ & 0.127 & 1 & 0.127 & 4.7 & 0.003 \\
\hline $\mathrm{T} \times \mathrm{NaCl}$ & 0.053 & 1 & 0.053 & 2.0 & 0.034 \\
\hline $\mathrm{XG} \times \mathrm{NaCl}$ & 0.047 & 1 & 0.047 & 1.7 & 0.043 \\
\hline Error & 0.099 & 11 & 0.090 & \multicolumn{2}{|c|}{$\mathrm{R}^{2}$} \\
\hline Total & 3.757 & 17 & - & \multicolumn{2}{|c|}{0.978} \\
\hline
\end{tabular}

Table 8. ANOVA analysis of initial gel strenght $\left(\mathrm{G}_{10 \mathrm{~s}}\right)$.

\begin{tabular}{|c|c|c|c|c|c|}
\hline Source of variation & SS & df & MS & F/F-critical & p-value \\
\hline Temperature $(\mathrm{T})$ & 30.250 & 1 & 30.250 & 20.1 & 0.000 \\
\hline Xanthan Gum (XG) & 56.250 & 1 & 56.250 & 37.3 & 0.000 \\
\hline $\mathrm{NaCl}$ & 6.250 & 1 & 6.250 & 4.1 & 0.005 \\
\hline T $x$ XG & 4.000 & 1 & 4.000 & 2.7 & 0.017 \\
\hline $\mathrm{T} \times \mathrm{NaCl}$ & 0.000 & 1 & 0.000 & 0.0 & 1.000 \\
\hline $\mathrm{XG} \times \mathrm{NaCl}$ & 0.000 & 1 & 0.000 & 0.0 & 1.000 \\
\hline Error & 5.528 & 11 & 0.503 & \multicolumn{2}{|c|}{$\mathrm{R}^{2}$} \\
\hline Total & 102.278 & 17 & - & \multicolumn{2}{|c|}{0.946} \\
\hline
\end{tabular}

Table 9. ANOVA analysis of final gel strenght $\left(\mathrm{G}_{10 \mathrm{~m}}\right)$.

\begin{tabular}{lccccc}
\hline Source of variation & SS & df & MS & F/F-critical & p-value \\
\hline Temperature (T) & 100.000 & 1 & 100.000 & 56.1 & 0.000 \\
Xanthan Gum (XG) & 156.250 & 1 & 156.250 & 87.8 & 0.000 \\
$\mathrm{NaCl}$ & 20.250 & 1 & 20.250 & 11.3 & 0.000 \\
$\mathrm{~T} \times \mathrm{XG}$ & 36.000 & 1 & 36.000 & 20.3 & 0.000 \\
$\mathrm{~T} \times \mathrm{NaCl}$ & 1.000 & 1 & 1.000 & 0.5 & 0.221 \\
$\mathrm{XG} \times \mathrm{NaCl}$ & 0.250 & 1 & 0.250 & 0.3 & 0.523 \\
Temperature (T) & 6.528 & 11 & 0.593 & $\mathrm{R}^{2}$ & 0.980 \\
Total & 320.278 & 17 & - & & \\
\hline
\end{tabular}

Thus, these sources of variation did not appear in the final generated model (Equation 3). As shown in Figure 3, " $n$ " increases with decreasing xanthan gum concentration and with increasing temperature and $\mathrm{NaCl}$ concentration.

It is reported that the pseudoplastic behavior of the macromolecule solution could be ascribed to the disentanglement of its long chain molecules, which reduces the intermolecular resistance to flow under shear conditions ${ }^{8}$.

When there is aggregation of the particles in a colloidal system, an increase in shear rate tends to result in fragmentation of these aggregates, resulting in a decrease in apparent viscosity. An increase in temperature causes the kinetic energy of the molecules to increase, hindering the formation of these aggregates and decreasing therefore the fluid pseudoplasticity.

With the increase of ionic strength on the system from increasing electrolytes concentration $\left(\mathrm{Na}^{+}\right)$, there is a decrease in hydrodynamic volume of xanthan gum. Since there is a smaller volume of polymer for intermolecular interactions, the molecular clusters formed at low shear rates are weaker, decreasing the dispersion pseudoplasticity ${ }^{9}$.

According to $\mathrm{p}$-values and $\mathrm{F} / \mathrm{F}$-critical ratios shown in Table 7, all effects were significant at a significance level of $95 \%$. Therefore, all variables influence " $k$ " and were taken into account in the generated model, as seen in Equation 4.

A xanthan gum concentration increase causes a gain in the flow consistency index value as shown in Figure 4. This parameter indicates the degree of fluid flow resistance. The higher the value of " $k$ ", the higher the viscosity of the fluid $^{10,11}$. As a viscosifying agent, an increase in the polymer concentration favors the intermolecular and cross link interactions due to the effective increase in the macromolecule dimensions and molar mass ${ }^{12}$.

The electronic repulsions between charges along the polymer backbone stretch and elongate individual chains. The counter-ions surround the xanthan gum chains to balance the 
charges on the polymer chain. The extended configuration of xanthan gum chains are closely related with some rheological properties of solutions with this polymer. In xantham gum solutions with $\mathrm{NaCl}$, the addition of counter ions allows the chain of xanthan gum to order and assume a smaller, more compact structure. The degree of shrinkage depends on the chain rigidity. In these solutions, the compact polymer chains lead to a reduction in the resistance to flow, ie, the consistency index and apparent viscosity ${ }^{13}$.
As in the flow behavior index analysis, not all effects were significant at the $95 \%$ confidence level for the thixotropic parameters (tables 8 and 9). This means that not all effects were taken into account in the generated models for the initial and final gel strength as shown in Equations 5 and 6 respectively. As can be seen in Figures 5 and 6, the two thixotropic parameters increase with increasing xanthan gum concentration and decreases with increasing temperature and $\mathrm{NaCl}$ concentration.

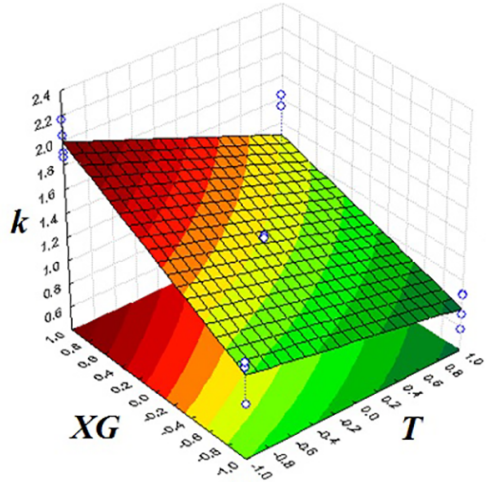

(a)

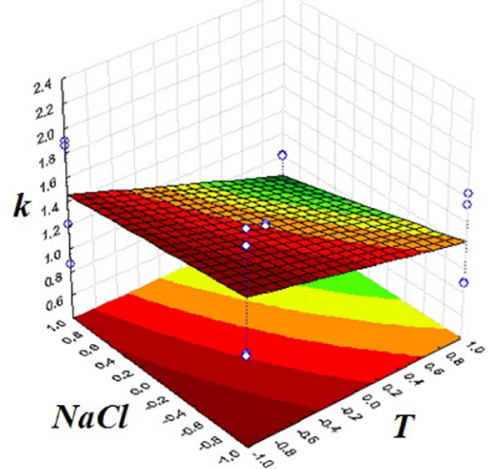

(b)

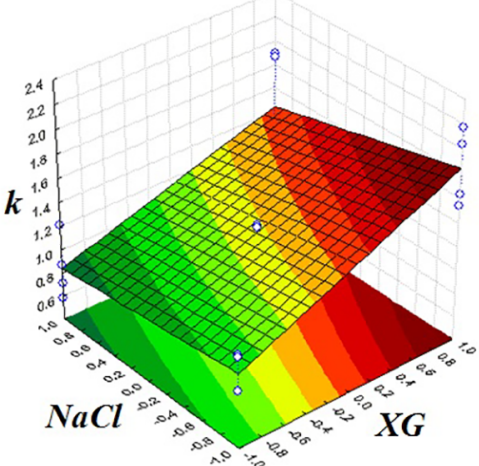

(c)

Figure 3. Response surfaces for " $n$ " by setting the $\mathrm{NaCl}$ concentration (a), xanthan gum concentration (b) and temperature (c).

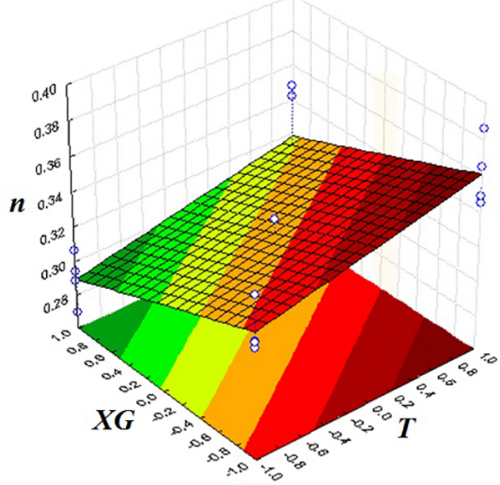

(a)

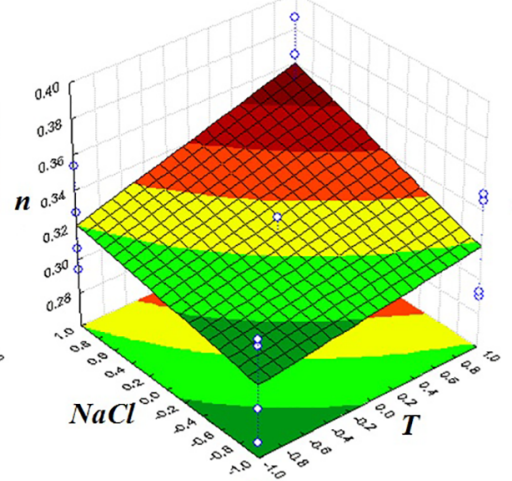

(b)

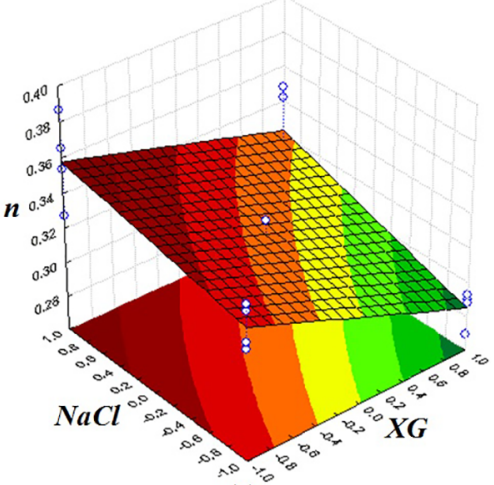

(c)

Figure 4. Response surfaces for " $k$ " by setting the $\mathrm{NaCl}$ concentration (a), xanthan gum concentration (b) and temperature (c).

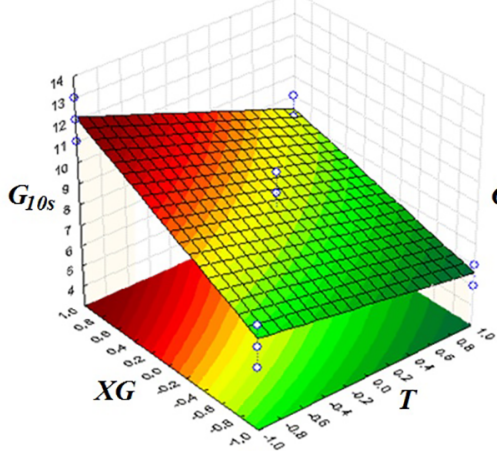

(a)

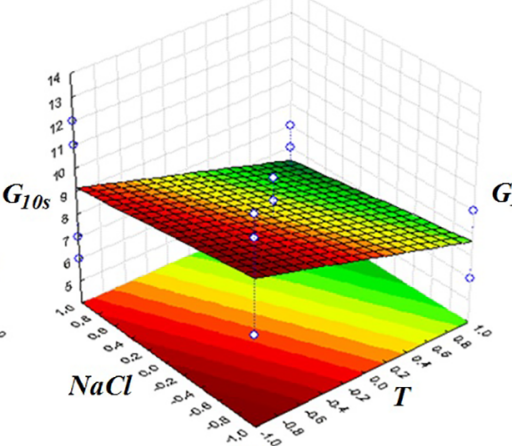

(b)

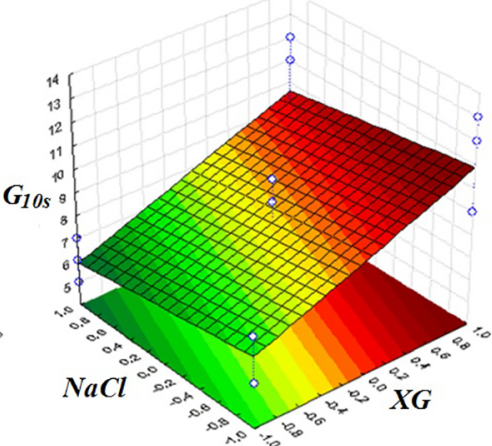

(c)

Figure 5. Response surfaces for " $\mathrm{G}_{10 \text { s }}$ " by setting the $\mathrm{NaCl}$ concentration (a), xanthan gum concentration (b) and temperature (c). 


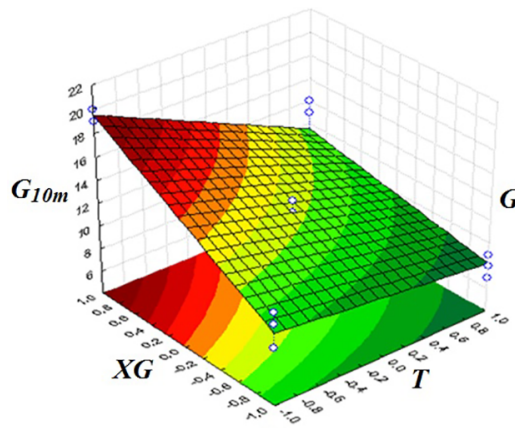

(a)

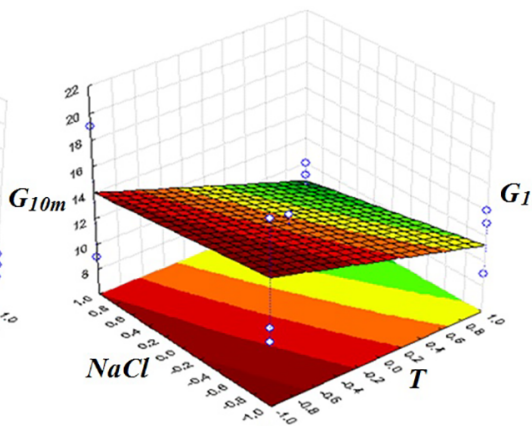

(b)

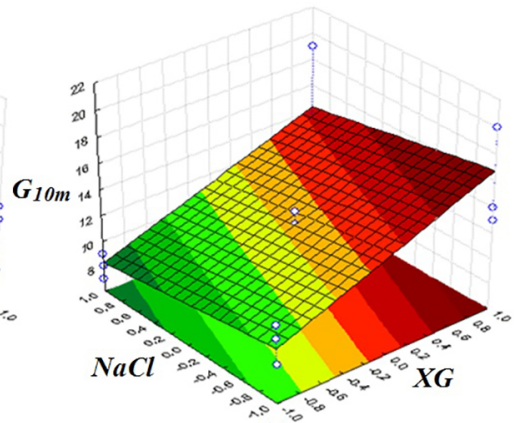

(c)

Figure 6. Response surfaces for " $\mathrm{G}_{10 \mathrm{~m}}$ " by setting the $\mathrm{NaCl}$ concentration(a), xanthan gum concentration (b) and temperature (c).

Increasing the salinity solution reduces the thixotropic parameters of xanthan gum. This reduction depends on the type of salt and the type of polymer microorganism producer. Increasing the salt concentration in solution modifies the gel-like structure formed during the static period. For the concentration range examined, this modification reduces gel formation ${ }^{14}$.

The bentonite interactions with electrolytes is another reason why there is a variation of these parameters. The thixotropy reduction due to presence of bentonite is attributed to clay particles aggregation in order to buid gel structures. The electrolyte addition causes a change in these structures due to compression of the electrical double layer due to the presence of $\mathrm{Na}^{+}$ions. The addition of salt leads to a decrease of the shear stress for a given range of shear rate ${ }^{15}$.

Once the electric double layer forces are related to gel structure formations, a change in the electric double layer reflects in changes in the fluid behavior. The reduction of the shear stresses is attributed to compression of the double layer that supports the entire bentonite clay particles structure 5

\section{Conclusion}

The screening step results showed that the calcium chloride does not influence significantly neither thixotropic nor rheological parameters.

After selection of variables, a full factorial design $2^{3}$ showed that both consistency and flow behavior indexes are influenced by temperature, xanthan gum and sodium chloride concentrations, as well as some of their first order interactions. The increase of temperature and sodium chloride concentration resulted in an increase in " $n$ ", reducing the fluid pseudoplasticity and caused a decrease in " $k$ ". Increasing xanthan gum concentration caused the opposite effect: a reduction in " $n$ " and a increasing in " $k$ ".

In the same design, the thixotropic parameters also showed dependence of the three independent variables. The increase of temperature and sodium chloride concentration led to a decrease in the thixotropic parameters while increasing xanthan gum concentration caused an increase on them.

\section{Acknowledgment}

The authors would like to acknowledge Universidade Federal da Bahia for their support and encouragements.

\section{References}

1. Thomas JE. Fundamentos de Engenharia de Petróleo. Rio de Janeiro: Interciência; 2004.

2. Petrobras. Manual de Fluidos. Rio de Janeiro: Petrobras; 2011.

3. Amorin LV, Farias KV, Barbosa MIR, Pereira E, França KB, Lira HL, et al. Fluidos de perfuração de base água. Parte I: Efeitos de aditivações poliméricas nas propriedades reológicas. Cerâmica. 2005;51(318):128-138. DOI: 10.1590/S036669132005000200010

4. M-I SWACO. Engineering Drilling Fluids Manual. Houston: Schlumberger; 2001.

5. Gray GR, Darley H. Fluidos de perfuração e completação. Rio de Janeiro: Elsevier; 2014.

6. American Petroleum Institute. API 13B1: Recommended Practice for Field Testing Water-based Drilling Fluids. Washington: American Petroleum Institute; 2014.

7. Box G, Hunter W, Hunter JS. Statistics for experimenters: An introduction to design, data analysis and model building. Hobboken: John Wiley \& Sons; 1978.

8. Wang B, Wang LJ, Li D, Özkan N, Li SJ, Mao ZH. Rheological properties of waxy maize starch and xanthan gum mixtures in the presence of sucrose. Carbohydrate Polymers. 2009;77(3):472481. DOI: $10.1016 /$ j.carbpol.2009.01.017

9. Heyman B, De Hertogh D, der Meeren PV, Depypere F, Dewettinck $\mathrm{K}$. Influence of xanthan transition on the rheological properties of waxy starches. Carbohydrate Polymers. 2013;96(2):568-577. DOI: 10.1016/j.carbpol.2012.10.077

10. Borges CD, Vendruscolo CT, Martins AL, Lomba RFT. Comportamento reológico de xantana produzida por Xanthomonas arboricola pv pruni para aplicação em fluido de perfuração 
de poços de petróleo. Polímeros. 2009;19(2):160-165. DOI: 10.1590/S0104-14282009000200015

11. Assis DJ. Influência da aeração e agitação nas propriedades das gomas xantana produzidas por Xanthomonas campestris mangiferaeindicae 2103 com glicerina residual do biodiesel: otimização e cinética do bioprocesso. [Master's dissertation]. Salvador: Universidade Federal da Bahia; 2013.

12. Xu L, Xu G, Liu T, Chen Y, Gong H. The comparison of rheological properties of aqueous welan gum and xanthan gum solutions. Carbohydrate Polymers. 2013;92(1):516-522. DOI: 10.1016/j.carbpol.2012.09.082
13. Hong CH, Choi HJ, Zhang K, Renou F, Crisel M. Effect of salt on turbulent drag reduction of xanthan gum. Carbohydrate Polymers. 2015;121:342-347. DOI: 10.1016/j.carbpol.2014.12.015

14. Achayuthakan P, Suphantharika M. Pasting and rheological properties of waxy corn starch as affected by guar gum and xanthan gum. Carbohydrate Polymers. 2008;71(1):9-17. DOI: 10.1016/j.carbpol.2007.05.006

15. Souza GS. Caracterização reológica de dispersões argilosas com goma xantana para fluidos de perfuração de poços de petróleo: influência de sais monovalentes, bivalentes e da temperatura. [Master's dissertation]. Salvador: Universidade Federal da Bahia; 2016. 